\title{
Modulation of olfactory signal detection in the olfactory epithelium: focus on the internal and external environment, and the emerging role of the immune system
}

\author{
Bertrand Bryche $^{1} \cdot$ Christine Baly $^{2} \cdot$ Nicolas Meunier $^{1}$ (1)
}

Received: 16 October 2020 / Accepted: 26 April 2021 / Published online: 7 May 2021

(c) The Author(s), under exclusive licence to Springer-Verlag GmbH Germany, part of Springer Nature 2021

\begin{abstract}
Detection and discrimination of odorants by the olfactory system plays a pivotal role in animal survival. Olfactory-based behaviors must be adapted to an ever-changing environment. Part of these adaptations includes changes of odorant detection by olfactory sensory neurons localized in the olfactory epithelium. It is now well established that internal signals such as hormones, neurotransmitters, or paracrine signals directly affect the electric activity of olfactory neurons. Furthermore, recent data have shown that activity-dependent survival of olfactory neurons is important in the olfactory epithelium. Finally, as olfactory neurons are directly exposed to environmental toxicants and pathogens, the olfactory epithelium also interacts closely with the immune system leading to neuroimmune modulations. Here, we review how detection of odorants can be modulated in the vertebrate olfactory epithelium. We choose to focus on three cellular types of the olfactory epithelium (the olfactory sensory neuron, the sustentacular and microvillar cells) to present the diversity of modulation of the detection of odorant in the olfactory epithelium. We also present some of the growing literature on the importance of immune cells in the functioning of the olfactory epithelium, although their impact on odorant detection is only just beginning to be unravelled.
\end{abstract}

$\begin{array}{ll}\text { Abbreviations } \\ \text { EOG } & \text { Electro-olfactogram } \\ \text { OB } & \text { Olfactory bulb } \\ \text { OE } & \text { Olfactory epithelium } \\ \text { OR } & \text { Olfactory receptor } \\ \text { OSN } & \text { Olfactory sensory neuron } \\ \text { SC } & \text { Sustentacular cells } \\ \text { BC } & \text { Basal cell } \\ \text { MvC } & \text { Microvillar cell } \\ \text { OBP } & \text { Olfactory binding protein } \\ \text { NALT } & \text { Nasal associated lymphoid tissue }\end{array}$

Nicolas Meunier

nicolas.meunier@inrae.fr

1 Université Paris-Saclay, INRAE, UVSQ, 78350 Jouy-enJosas, VIM, France

2 Université Paris Saclay, INRAE, UVSQ, BREED, 78350 Jouy-en-Josas, France

\section{Introduction}

In almost all sensory systems, sensory inputs are affected by external and internal stimuli allowing the adaptation of organisms to their environment. The most effective external stimuli are related to nociception which drives complex and major alterations in the animal behavior (Herz 1998). Internal signals such as hormones, neurotransmitters, or paracrine signals also influence sensory systems (McGann 2015). The vertebrate olfactory system is no exception to this rule. The olfactory peripheral system is mainly composed of the olfactory epithelium (OE) with the additional vomeronasal organ (VNO) in most mammals. Some mammals also have two, spatially segregated, clusters of chemosensory neurons: the septal organ of Masera and the Grueneberg ganglion (Hayden and Teeling 2014). The present review will be limited to modulation at the level of the main OE. In vertebrates, the OE is composed of three major cell types (Fig. 1): ciliated bipolar olfactory sensory neurons (OSNs), which are the main receptor cells detecting odorants; sustentacular cells (SCs), which support OSN activity; and basal cells (BCs), which are the stem cells of the OE (Hayden and Teeling 2014). BCs allow a continuous renewal of the $\mathrm{OE}$ cells which are exposed to toxins and pathogens leading to cellular death. In addition to these main cell types, microvillar cells (MvCs) form a 
Fig. 1 Schematic representation of the regulatory roles of each of the main cells of the olfactory epithelium $(\mathrm{OE})$ that are covered by this review. Each cell type is represented in a colored plain or dotted circle, green for OSN, yellow for sustentaculars cells (SCs), red for microvillar cells (MvCs), and blue for immune cells. Each circle contains information about its main role in OE modulation (box) with key references whose color indicates the species the study is based on. Some studies refer to complementary functions (fused circles), mixed functions (half-colored), or putative functions (dotted circles)

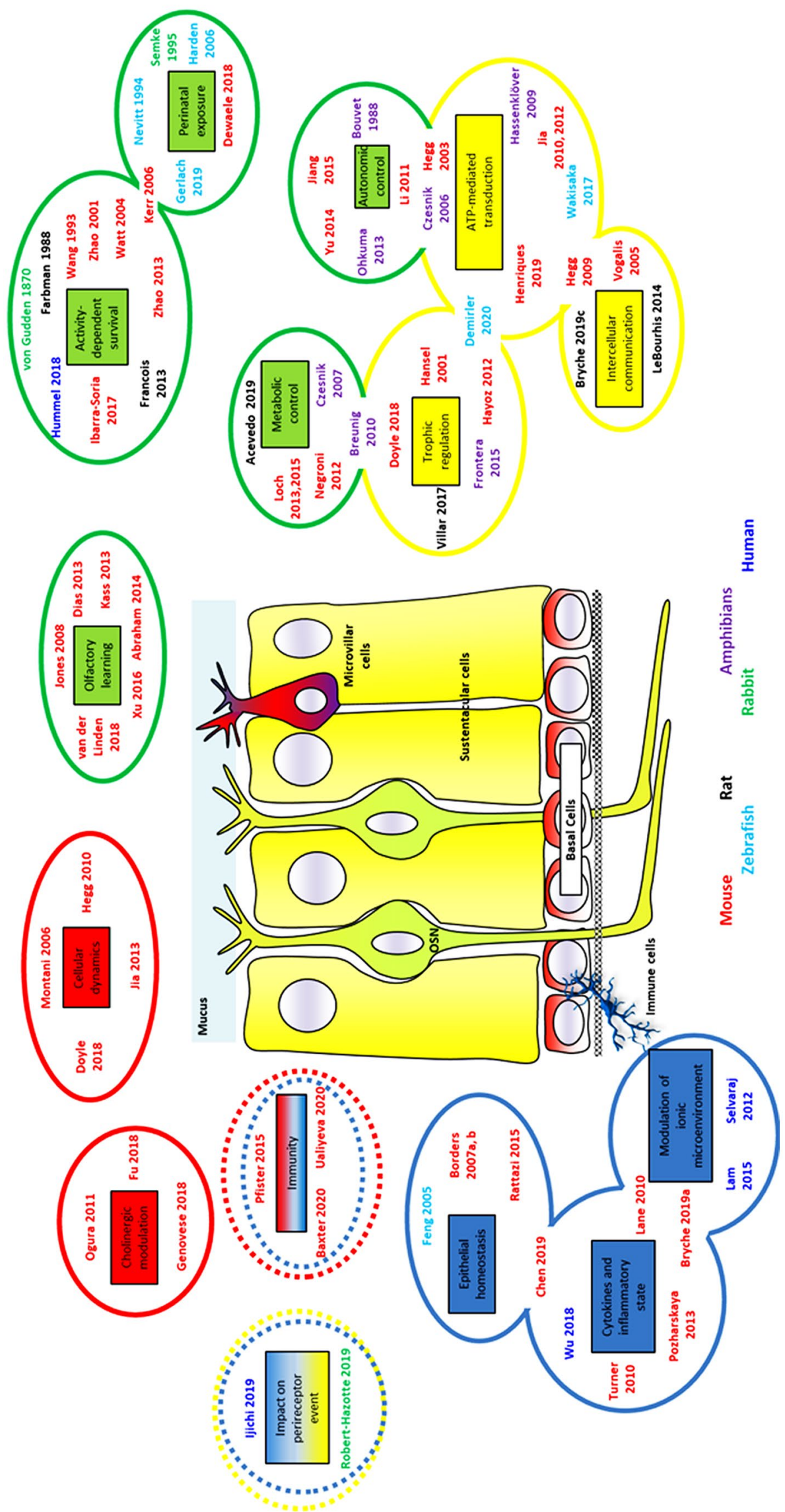


heterogeneous population of non-neuronal superficial cells mainly described in rodents but also in canines and primates (Miller et al. 1995; Elsaesser and Paysan 2007). Apart from the OSNs, which have been extensively studied, the precise roles of other cell types are less clear, but recent work shows that they participate to olfactory signal modulation. In this review, we will focus on the changes in the olfactory sensory input in response to variations in the internal and external environment which acts at the level of OSNs, SCs, and MvCs. We will discuss short-term changes of the response to odorants linked to a change in circulating hormones such as insulin as well as long-term changes linked to OSN population plasticity. In addition, immune cells are present in the $\mathrm{OE}$ (Mellert et al. 1992; Imamura and Hasegawa-Ishii 2016) and recent studies show that they can affect the response of OSN (Bryche et al. 2019a; Ualiyeva et al. 2020). Furthermore, recent reports of COVID-19-related olfactory disorders in humans highlight the importance of immune cells in the $\mathrm{OE}$ (Rodriguez et al. 2020; Bryche et al. 2020; Le Bon and Horoi 2020). We will describe the emerging role of these cells in the regulation of olfactory signal, in physiological situations (through the homeostatic presence of resident immune cells or immune components) and in pathological situations.

\section{Modulation of the olfactory sensory neurons}

OSNs are the receptor cells for the sense of smell, and their cell bodies are found in the OE, lining the nasal cavity. These neurons have a single dendrite, terminating in a knob covered in cilia and submerged in mucus that is in direct contact with the external environment. Olfactory receptors (ORs) are present in the cilia and are activated by odorants. One mature OSN expresses only one of the OR genes among hundreds found in vertebrate genomes. OSN axons project directly to the olfactory bulb (OB) in the central nervous system. In this section, we will first discuss how olfactory stimulation can shape OSN population and secondly the influence of internal messengers.

\section{Activity-dependent survival of OSN}

Plasticity was long thought to be solely occurring in the central nervous system, but it is now clearly established that it also takes place in the peripheral nervous system, including the $\mathrm{OE}$ (McGann 2015). Part of this plasticity depends on the direct stimulation of OSNs by odors, and recent data clearly show that the context of odorant exposure differentially impacts the neuronal population. We will thus distinguish between odors without association to a specific stimulus, which we will refer as "passive stimulation," and stimulation linked to a learning task, where odors are associated with a specific stimulus.

\section{Impact of odorants}

Since the pioneer works on motor neurons in chick embryos (Hollyday et al. 1977), the link between survival and activity of neurons is well established. The $\mathrm{OE}$ of vertebrates is a highly regenerative neuroepithelium that is maintained under normal conditions by a population of stem and progenitor cells. Due to this renewal capacity, it has been postulated that the population of OSNs has the potential to be shaped by environmental factors.

The first experiments to test effects of odorant stimulation on the OSN population were based on unilateral nostril occlusion (Gudden 1870). Unilateral nostril occlusion prevents stimulation of OSNs in the occluded nostril. According to the activity-driven survival hypothesis, OSN death rate should be higher compared to the non-occluded side. However, the occlusion also limits damages from inhaled pathogens and irritants, while amplifying them on the non-occluded side because the air flow is increased into the solely functional nostril. Thus, results obtained from unilateral nostril occlusions are difficult to interpret and often controversial (Farbman et al. 1988; Fitzwater and Coppola 2021). An interesting review by Coppola (2012) clearly describes biases and limitations of this experimental model. Nevertheless, some studies clearly show that the dynamic of OSN population is affected differentially in terms of the expressed OR populations, indicating that sensory experience could shape the olfactory response of the OE (He et al. 2012; Zhao et al. 2013; van der Linden et al. 2020).

Genetic tools offer another experimental approach to examine activity-dependent survival of OSNs. In mice, Zhao and Reed (2001) took advantage of the X chromosome location of the $\mathrm{OCNCl}$ gene, one of the key genes in olfactory transduction, encoding an essential subunit of the olfactory cyclic nucleotide gated channel, which is essential for the depolarization of OSNs (Reisert and Reingruber 2019). In their study, Zhao and Reed replaced $O C N C l$ with the $B$-galactosidase reporter gene, allowing a direct visualization of $O C N C 1$-deficient olfactory neurons and their projections. In all female cells, one of the $\mathrm{X}$ chromosomes is inactivated randomly. Therefore, in heterozygous females, OSNs will randomly express either the ß-galactosidase or the olfactory cyclic nucleotide gated channel. Of the total OSN population, $50 \%$ are thus active, while the other inactive $50 \%$ are easily stained blue due to their reporter gene expression. If at birth, the OSN population in the OE reflected this proportion, the blue-stained OSN proportion dropped dramatically after one month. These results are consistent with the hypothesis that only active OSNs survive. Another study confirmed this result by overexpressing an OR activated by octanal in the OE (Watt et al. 2004). The authors found that the OSN population expressing this OR increased in 
presence of octanal, consistent with an activity-dependent survival of OSNs in the OE.

A simpler experimental approach consists of exposure to different odors. The first clear demonstration was carried out on mice by measuring the evolution of the electrophysiological response in the OSN population, after repeated androstenone exposure (Wang et al. 1993). The authors observed a specific increase in the response to this odor, supporting the activity-dependent survival hypothesis. Alternatively, one can hypothesize that this change would be caused by an increase in the individual response of androstenone-sensitive OSNs through improvement in efficiency of the transduction pathway (Fig. 2). This second hypothesis was favored by another study, using genetically engineered mice expressing a reporter gene associated with a single OR (Kerr and Belluscio 2006). In this work, the authors manually counted the number of OSNs expressing an OR sensitive to octanal; this number did not change when the animals were exposed to this odorant. However, subsequent studies using a similar manual counting of the OSN population found opposite results with an increase in the number of OSNs expressing a stimulated OR by acetophenone or heptanal (François et al. 2013; Cadiou et al. 2014). Such discrepancies between studies indicate that activity-dependent survival might be influenced by the odorization protocol and is unlikely to be similar for all types of OSN, dependent on the OR they express

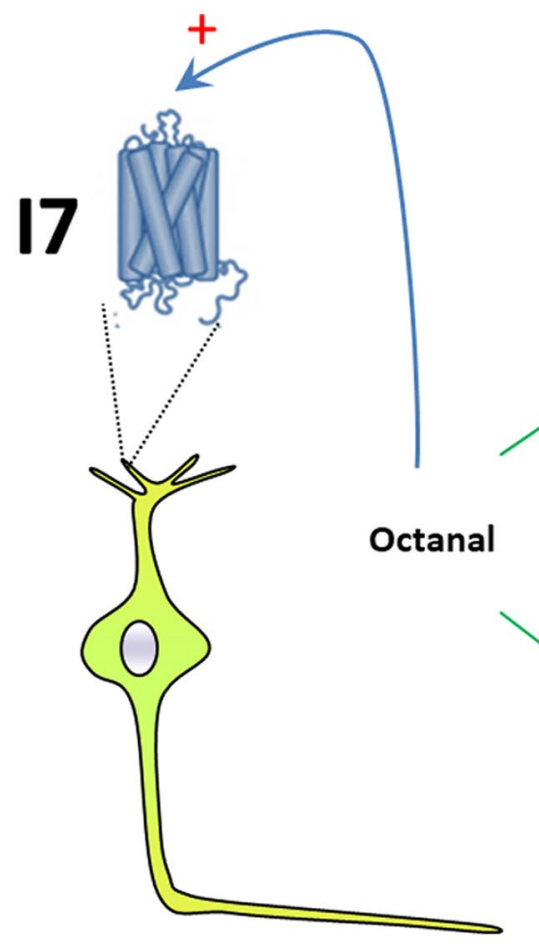

\section{Activity-dependent survival mechanism}
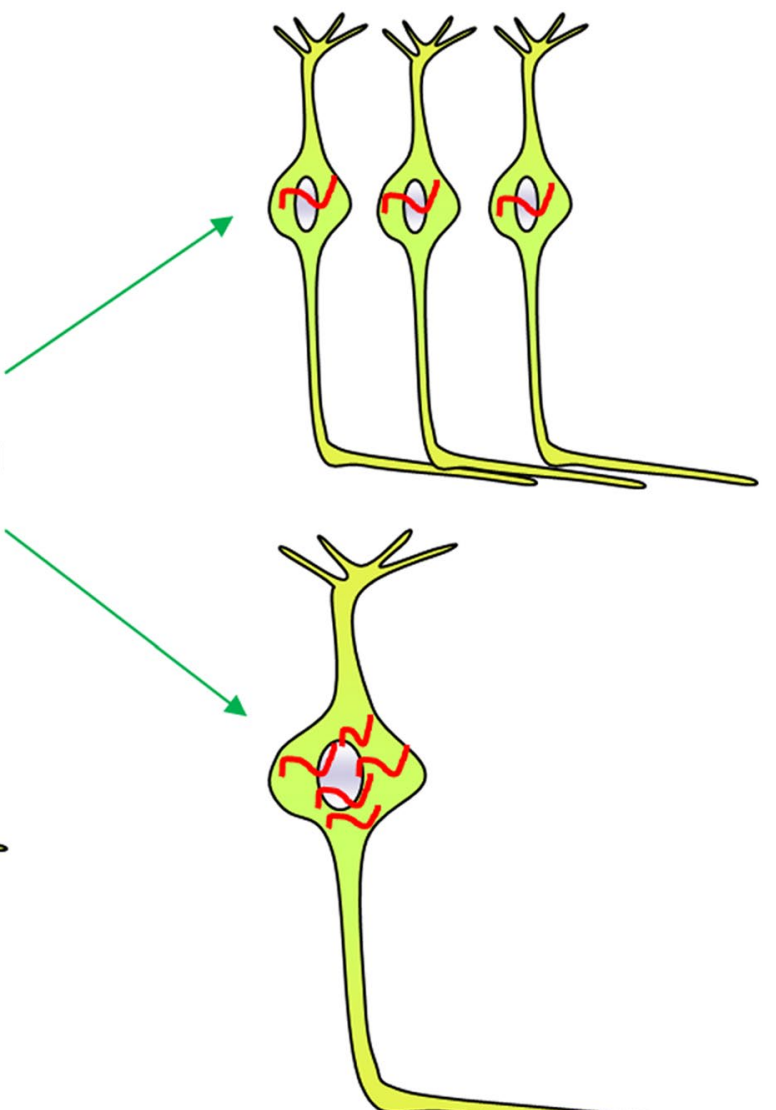

\section{Up-regulation of olfactory receptor or transduction pathway related gene expression}

Fig. 2 Impact of the presence of an odorant on olfactory sensory neuron populations. Numerous studies have shown that the exposure to a broad range of odorant increases the response of the olfactory epithelium. Here, olfactory sensory neurons (OSNs) expressing the olfactory receptor I7 are stimulated most efficiently by octanal. Two different hypotheses can explain this change. Either the OSN popula- tion sensitive to this odorant increases through an activity-dependent survival mechanism (upper arrow), or the stimulated OSNs increase their response to the given odorant through an up-regulation of olfactory receptor gene expression or another mechanism improving the transduction pathway (lower arrow) 
as well as the odorant used (Fitzwater and Coppola 2021). This is well illustrated by a review on the modulation of OR genes expression in the OE through activity-dependent mechanism (Wang et al. 2017).

A systematic study explored if activity-dependent survival of OSNs differs according to the OR they express. Using transcriptomics, the authors measured the evolution of mRNA levels coding for all ORs in the OE of mice living in various odorant environments (Ibarra-Soria et al. 2017). Based on the assumption that a given population of OSN expressing a specific OR is reflected by the mRNA level of this OR, they showed that only a small number of OSN subtypes are modulated by odorants. Furthermore, odorants must be present discontinuously, probably to limit the desensitization of the OSN. However, another study examining the impact of olfactory learning on OSN population plasticity (van der Linden et al. 2018) found that the correlation between a given population of OSNs and the mRNA level of ORs in the whole OE holds true only for part of the OSN population. Overall, these studies show that activitydependent modulation of OSN activity may be controlled not only at the level of the OSN population but also by changing the transduction efficiency at the level of a single neuron (Fig. 2). The mechanism behind the tuning of the OSN population to the odorant environment remains mostly unexplored.

While all these studies have been performed in rodents, one group examined whether this plasticity also occurred in humans (Hummel et al. 2018). When participants were trained daily to smell a few odorants for 4-6 months, the amplitude of electro-olfactogram (EOG) recordings was increased. However, the effect was increased in response to all odorants tested by EOG, including the control odorants that were not used during the inhalation training. This result could be related to a global increase of olfactory performance after training due to central nervous system plasticity. More experiments are needed to show that activity driven survival of OSN is also a reality in humans.

\section{Olfactory learning and OSN plasticity}

In all the aforementioned experiments, odorant stimulations were used without associated cues. They can therefore be considered to involve "passive exposure" to odorants in contrast to the stimulus-associated odorants used in classical Pavlovian paradigms of associative learning (Herz 1998; McGann 2015). Here, we present studies specifically investigating the OE neuroplasticity during olfactory associated learning. The first study, performed by the Ressler group in 2008, explored the evolution of the OSN population sensitive to acetophenone during either aversive or appetitive conditioning in mice (Jones et al. 2008). For both conditionings, an increase was observed in the
OSN population expressing Olfr 151, an OR sensitive to acetophenone. Astonishingly, this associative learning in males was transmitted to the progeny which also displayed an increased representation of Olfr 151-expressing OSNs in the OE (Dias and Ressler 2014). While this process could be reversed through extinction training (Morrison et al. 2015), the mechanism behind such intergenerational plasticity is still unknown, but probably involves epigenetic transmission of information. Indeed, the authors identified new epigenetic marks (i.e., methylation of cytosines followed by guanine residues in $\mathrm{CpG}$ sites) in the spermatozoid genome at the level of the Olfr151 promoter, following an associative learning task with acetophenone. It remains to be determined how an integrated signal resulting in associative learning in the brain could impact DNA methylation in spermatozoa. Nevertheless, epigenetic marks induced by the neuronal activity may be essential for the activity-dependent plasticity of the OSN population. One key actor may be one of the DNA (cytosine-5)-methyltransferases (DNMTs), which are specific enzymes that cause methylation at $\mathrm{CpG}$ sites. Indeed, another group identified DNMT3A as necessary to ensure proper methylation of odorant-activated genes in OSNs (Colquitt et al. 2014).

Two research groups have also observed strong plasticity of the OSN population following associative learning. One study used odor-based fear conditioning (Kass et al. 2013b) and another go/no-go olfactory training (Abraham et al. 2014). Go/no-go olfactory training consists at obtaining a reward during a "Go" stimulus and at withholding the response for the "NoGo" stimulus (another odor usually similar to the first odor; Berditchevskaia et al. 2016). The modulation was observed in the $\mathrm{OB}$ at the level of the glomeruli by measuring OSN synapse activity. In both studies, this activity was increased following odor-based learning with a specificity of the OSN population responding to the odorant used. Interestingly, both studies investigated the impact of "passive exposure" without associated learning, which did not change the OSN output in the OB. This result confirms that the impact of "passive odorant exposure" on the OSN population is restricted to a few odorants (Ibarra-Soria et al. 2017) and probably less effective compared to learning tasks. However, while both studies observed that OSN are more effectively stimulated by an odorant previously used in a learning task, the authors did not evaluate if (1) the number of OSNs sensitive to the odorants used during learning was changed (although one group observed fast plasticity, after 3 days of associative learning (Kass et al. 2013b), which would not be consistent with significant OSN population changes); (2) the existing OSNs were more efficient in transmitting their information (Fig. 2); (3) a modification of the local circuitry through direct modulation by interneurons of OSN synapse effectiveness was involved. 
While most studies focused on the main OE, one study explored the plasticity of OSNs in the VNO specialized in the detection of odorants with low volatility (Xu et al. 2016). In this study, $\mathrm{Xu}$ et al. evaluated an OSN population present only in males and activated specifically by a sulphated steroid present in female urine. Using calcium imaging, the authors observed that this OSN population became less responsive following co-housing with females. This effect could potentially be related to a diminution of the OSN number, which would be in contradiction to the results observed previously on the main OE. This difference was investigated further in another study focusing on the impact of co-housing of male and female mice on OSN populations in both the VNO and the main OE (van der Linden et al. 2018). In this work, the authors found that there is an optimal level of stimulation of OSNs in order to increase their lifespan through activity-dependent mechanisms. Interestingly, they observed that olfactory learning may impact both OSN population size and OR transcript levels in one OSN (Fig. 2) in contrast to other reports on passive odorant exposure, where only changes in the OSN population number were observed (Ibarra-Soria et al. 2017).

Perinatal exposure to odorants is a particular form of associative learning as the odorants will be associated to the maternal presence. This is nicely demonstrated by the work on odor cues inducing suckling in mice pups (Logan et al. 2012). In this study, the authors observed that pups initiate suckling thanks to the presence of amniotic fluid around the dam's nipples (present because the mother licks her own ventrum following birth). Mice pups probably learned these odors in utero as suckling can also be initiated in the presence of an artificial odorant around a washed nipple if the mother's diet was flavored with this odor during gestation. It suggests that the OSN population could be tuned to the odorant environment as early as during the perinatal period. The first study to explore the impact of prenatal odorant exposure on the $\mathrm{OE}$ was done in rabbits (Semke et al. 1995). In this study, pregnant rabbits were fed juniper berries and the authors recorded the electrophysiological response of the $\mathrm{OE}$ of the pups a few days after birth. They found a specific increase in the electrophysiological response to juniper oil in exposed pups in comparison to control pups which were not exposed to juniper berries. These results indicate that the OSN population can display an early plasticity similar to that observed in adults. These results contrast with other studies using other periods of exposure. Adding the odorant heptanal to the maternal food, during gestation then lactation specifically decreased the electrophysiological response of pup OSN to it (Dewaele et al. 2018). Other studies using an exposure limited to the postnatal period showed no effect on the OSN population (Kerr and Belluscio 2006; Monjaraz-Fuentes et al. 2017). Inducing plasticity at the level of the OE probably relies on the experimental conditions (odorant, concentration, type of exposure, period).
Olfactory-based memories are particularly important for imprinting, a mechanism well described in salmon which return to their natal river to reproduce. Such imprinting could be based on a tuning of the OE sensitivity to early exposure of odorants. A specific increase in the OEsensitivity to imprinted odorants has been recorded in adult salmon (Nevitt et al. 1994). Furthermore, a study in zebrafish reported an OR expression modulation in a model of imprinting (Harden et al. 2006). Contrastingly, a recent review concludes that so far there is no clear evidence of such a mechanism, and extensive data indicate that olfactory imprinting in zebrafish is not based on modulation of OR expression, but rather on central processing modulation (Gerlach et al. 2019).

\section{Concluding remark on OSN modulation by odorants}

The effects of odorants exposure on OSN modulation are still controversial, mainly relying on different odorization protocols. The addition of odorants in the diet or environment at non-physiological concentrations may lead to a toxicity, which is rarely measured. In addition, the maternal gestational stress linked to an abrupt dietary transition from non-odorized to odorized food might also stress the pups and lead to a decrease in the OSN response to odorants as demonstrated for animals raised in unpredictable stress conditions (Raynaud et al. 2015). The effect of stress on the OE may be linked to the effect of glucocorticoids affecting this neuroepithelium (Meunier et al. 2020). Studies dealing with environmental modulations of OSN activity may thus also consider internal factors which are presented in the next section.

\section{Direct modulation of OSN activity by internal signals}

OSNs express a great diversity of receptors to hormones and local mediators; these can modulate their electric activity directly. In the following section, we have selected some neuromodulators where molecular evidence of direct interaction with OSNs has been illustrated.

\section{Neurotransmitter: acetylcholine and OSN response potentiation}

The vertebrate olfactory mucosa receives parasympathetic and sympathetic innervation participating in the peripheral modulation of olfactory signals in specific resting or stressing contexts, respectively (Lucero 2013). A direct modulation of the electrical response of OSNs by autonomic messengers was described first in frogs for acetylcholine (Bouvet et al. 1988). In isolated newt OSNs, acetylcholine enhances excitability by lowering the threshold of spike generation in 
OSNs via the type 3 muscarinic acetylcholine receptor, M3 (Ohkuma et al. 2013). In mice, a M3 muscarinic acetylcholine receptor is expressed in the ciliary membrane of OSNs, which physically interacts with ORs to promote odorantinduced responses in vitro (Li and Matsunami 2011). The activation of $\mathrm{M} 3$ receptors amplifies OR activity by blocking the recruitment of $\beta$-arrestin 2 , a scaffolding protein involved in the internalization-mediated desensitization of OR (Jiang and Matsunami 2015). It is likely that acetylcholine is not exclusively released from nerve ends, but could be locally supplied from cholinergic paracrine neighbouring cells, e.g., MvCs as discussed in the dedicated section (Ogura et al. 2011; Saunders et al. 2014).

\section{Neurotransmitter: purinergic signaling and OSN inhibition}

Presence of purinergic P2X (ligand-gated ion channels) and P2Y (metabotropic) receptors on OSNs is well described, and their activation is associated with olfactory response modulation in mice, whereas they are mainly present on sustentacular and basal cells in Xenopus tadpoles (Hegg et al. 2003; Czesnik et al. 2006). In mice, exogenous and endogenous ATP activates both receptors types to modulate the odor responsiveness, reducing odor-induced calcium transients in the majority of OSNs. Another study has shown that OSNs express distinct combinations of purinergic receptors leading to differential changes of OSN activity according to the OR expressed (Yu and Zhang 2014). Indeed, the response amplitude evoked by a mixture of ATP and benzaldehyde was half of that evoked by benzaldehyde alone, while a mixture of ATP and acetophenone evoked amplitudes similar to that evoked by acetophenone alone. Besides this direct impact on sensory signal transduction, detailed insights into other physiological properties and the functional significance of purinergic signalling in olfaction have been recently reviewed (Rotermund et al. 2019).

\section{Hormones and peptides related to metabolic status}

The OE is sensitive to the metabolic status of the animal, which could directly change odorant detection as OSNs express hormone receptors from the dendritic knob to the axon (Palouzier-Paulignan et al. 2012). In rodents, several metabolic factors exert short-term effects on electrophysiological responses to odorants as recorded by EOGs or patch-clamp after ex-vivo local application. Anorexigenic hormones such as insulin and leptin decrease odorant sensitivity, whereas orexigenic peptides such as orexin increase odorant sensitivity a few minutes after their application. In the years following two reviews focused on this subject (Palouzier-Paulignan et al. 2012; Lucero 2013), the number of known factors related to metabolic status that change OSN activity has increased in vertebrates. Their effects remain consistent with their main metabolic action. A single in vivo local nasal application of adiponectin, an adipocyte-derived starvation signal, and of ghrelin, another starvation-related hormone from the gastro-intestinal tract, rapidly increases the response to odorants (Loch et al. 2013, 2015). Similarly, application of neuropeptide Y (NPY), an orexigenic peptide, increases the electrophysiological response of OSNs, but only in fasted rats (Negroni et al. 2012). Endocannabinoids, which impact energy metabolism and feeding behaviour, have been also investigated for their functional importance in the olfactory system (reviewed Terral et al. 2020). Endocannabinoids exert contrasting effects depending on the species and differences between mammalian and other vertebrates are noticed: an endocannabinoid system was first described in the tadpole OE with a neuronal expression of CB1 receptors and endocannabinoid 2-arachidonoylglycerol synthesis in both neurons and SCs (Czesnik et al. 2007; Breunig et al. 2010). The authors concluded that modulation of odorant detection in the OE of larval Xenopus laevis depended on the metabolic state of the animal. In the mouse OE, functional CB1 receptors have been identified, but endocannabinoids probably do not modulate olfaction in this species, as CB1/2deficient mice display intact olfactory-mediated behavioral performances, despite a significant loss in OSN population (Hutch et al. 2015). As in mammals, the presence of metabolic factors on olfactory organs in zebrafish suggests similar processes to control chemosensory stimuli (Montalbano et al. 2020).

\section{Concluding remarks on modulation of OSN by internal environment}

Several questions remain concerning the physiological relevance of these direct modulations of sensory signal transduction by internal factors:

1. What is the importance of peripheral versus central modulation in vivo?

Many studies on modulation of olfactory sensitivity are based on behavioural integrated approaches. However, the importance of a peripheral direct modulation of the responses of OSNs in the OE relative to the one driven by central pathways remains to be explored. Indeed, the central processing of olfactory information may be impacted by in vivo intranasal treatment diffusing through the blood brain barrier and thus treating solely the $\mathrm{OE}$ in vivo is challenging. It could explain why in humans, the impact of hormones inhalation on odor sensitivity could be contradictory, depending on the experimental conditions (Brünner et al. 2013; Schöpf et al. 2015). 
2. Is modulation of OSN activity a result of local action on cellular dynamics?

OSNs synthetize ligands for several metabolic receptors as demonstrated for orexin, leptin, and insulin, some of them being locally modulated by the nutritional or metabolic status (Caillol et al. 2003; Baly et al. 2007; Lacroix et al. 2008). As these ligands have known pleiotropic roles, they could have additional roles independently of a short-term metabolic regulation. This has been clearly demonstrated for ATP and NPY which act synergistically to control OSN renewal in adult OE (Jia and Hegg 2010). Participation of these factors in the regulation of cell dynamics in the OE could change OSN sensitivity to odorants by affecting their population through long-term effects.

\section{SCs}

SCs form a tightly packed columnar monolayer in the OE. These glial cells lie on the lamina propria and possess numerous long microvilli that intermingle with the cilia of the OSNs on the apical side of the OE. SCs closely enwrap OSNs (Liang 2020) providing mechanical, trophic, and metabolic support. They are known to be involved in the secretion of mucus, biotransformation of noxious chemicals and in phagocytosis of dying cells. Numerous studies show that SCs impact the detection of odorants.

\section{Indirect impact of SCs on OSN activity: focus on nucleotide signalling}

SCs are known to act on OSNs by producing a myriad of neuromodulator molecules, e.g., endocannabinoids, insulin, NPY, peptide YY (an anorexigenic peptide), brain-derived neurotrophic factor (BDNF), and ATP (Hansel et al. 2001; Czesnik et al. 2007; Breunig et al. 2010; Hayoz et al. 2012; Frontera et al. 2015; Henriques et al. 2019). Some of these factors modulate olfactory sensitivity such as endocannabinoids in fasted tadpoles as described in the above OSN section (Breunig et al. 2010). In addition, SCs express receptors for insulin, leptin, orexin, and purinergic factors, making them targets for autocrine or paracrine regulations that are likely to participate in the crosstalk between SCs and OSNs. Numerous modulations of SCs are related to nucleotide signalling in the $\mathrm{OE}$ and we will focus on these modulators here (Housley et al. 2009; Rotermund et al. 2019). SCs express metabotropic P2Y purinergic receptors. ATP initiates intraepithelial $\mathrm{Ca}^{2+}$ influx in both OSNs and SCs in Xenopus laevis (Czesnik et al. 2006; Hassenklöver et al. 2009) and modulates the odor-evoked electrical activity of OSNs in rodents (Hegg et al. 2003, 2009). An ATP-activated chloride channel has been recently identified in mice SCs which may participate in this modulation (Henriques et al. 2019). In addition to the direct impact of SCs on odorant signal transduction, purinergic agonists such as ATP, ADP, and UTP could also be involved in trophic functions, particularly when OSNs are overstimulated. Purinergic signalling is also involved in the cellular dynamics of the OE as ATP initiates a cascade for neuroprotection and regeneration upon injuries (Hayoz et al. 2012). In this context, intranasal instillation of ATP in mice upregulates NPY expression in SCs which induces basal progenitor cell proliferation via activation of NPY1 receptors (Jia and Hegg 2012; Jia et al. 2013). Detailed insights into purinergic signalling have been published recently in the vertebrate olfactory system (Rotermund et al. 2019). Recent work in zebrafish indicates a similar role for ATP in activating among others a subset of OSNs (Wakisaka et al. 2017; Demirler et al. 2020). SCs also indirectly modulate rat OSN activity through the release of glucose in the mucus, where it could be transported into the OSN cilia by the major glucose transporter Glut 3 and metabolized by glycolysis to generate ATP to ensure efficient olfactory transduction (Villar et al. 2017; Acevedo et al. 2019).

\section{Direct impact of SCs on OSN activity: GAP junction communication}

Gap junctions are composed of connexins and form a specialized intercellular connection between adjacent cells. They offer cytoplasmic continuity and electrical coupling between OSNs and SCs in the OE and therefore provide a pathway for intercellular communication (via $\mathrm{Ca}^{2+}$ and other signalling molecules-Vogalis et al. 2005; Hegg et al. 2009). Their importance in odorant sensitivity has been highlighted in a model of transgenic mice, for which an altered assembly of connexin-43 in OSNs reduces olfactory responses (Zhang 2010). In addition, acute treatment of $\mathrm{OE}$ with endothelin-1, one of the most potent vasoconstrictor peptides known to have pleiotropic roles (Masaki 2004) uncouples GAP junction in SCs (Le Bourhis et al. 2014). Concomitantly, endothelin-1 indirectly impacts OSNs response to odorants by delaying the repolarization kinetics of the olfactory responses (Bryche et al. 2019c). The mechanism behind such modulation remains to be clarified. It could be that endothelin-1 changes the SCs activity and impacts the maintenance of ionic concentration in the mucus which in turn would alter the OSN responses to odorants. It could also act simultaneously on OSNs as they are expressing connexins and are sensitive to endothelin-1 (Yu and Zhang 2015).

\section{Microvillar cells: impact on odorant detection and link with the immune system}

Microvillar cells (MvCs) are chemosensory cells scattered in the apical layer of the OE. They include various cell subtypes with similar characteristics, including an apical 
tuft of short microvilli protruding into the nasal cavity and a basal cytoplasmic process resembling a shortaxon-like process. At least three different types of MvCs have been described, based on their receptors and their signal transduction machinery, e.g., transient receptor potential cation channel subfamily M member 5 (TRPM5), 1-Phosphatidylinositol-4,5-bisphosphate phosphodiesterase beta-2 (PLC $\beta 2$ ), transient receptor potential cation channel subfamily C member 6 (TRPC6), and receptor for inositol 1,4,5-trisphosphate (IP3R3) (Elsaesser et al. 2005; Montani et al. 2006; Lin et al. 2008; Hansen and Finger 2008; Genovese and Tizzano 2018). Their relative abundance and their location at regular intervals along the $\mathrm{OE}$ in the mouse suggest that MvCs play an important role in olfactory tissue homeostasis and modulation. MvCs are clearly involved in the control of neurogenesis of the OE (Montani et al. 2006; Hegg et al. 2010; Jia et al. 2013; Doyle et al. 2018). Furthermore, TRPM5-positive MvCs respond directly to chemical and thermal stimulations (Elsaesser et al. 2005). They probably impact OSN detection of odorants indirectly by releasing messengers like acetylcholine (Ogura et al. 2011; Fu et al. 2018). Indeed, acetylcholine changes the activity of neighbouring SCs and OSNs through muscarinic receptors as detailed in the OSN section of the manuscript. Some MvCs also express high levels of interleukin-25 (IL25), and they generate cysteinyl leukotrienes in response to ATP or allergens indicating that they can elicit effector functions dedicated to local sentinel immune activities (Ualiyeva et al. 2020). They also selectively express a major regulator of mucus secretion and immune responsiveness, the cystic fibrosis transmembrane conductance regulator (CFTR) at their apical pole, whose knock-out impairs epithelial homeostasis, delays OE regeneration following methimazole-induced neurodegeneration and recruits inflammatory leukocytes (Pfister et al. 2015). A potential role for TRPM5-expressing cells in viral infection has been recently suggested, as a RNAseq library from MvCs displays an enrichment in molecules related to the inflammatory response elicited by viral infection of the OE (Baxter et al. 2020). Such a putative role of $\mathrm{MvC}$ as a sentinel against viral invasion remains to be confirmed by functional studies.

\section{The importance of the immune system in the olfactory epithelium}

Some studies have clearly demonstrated the importance of immune cells in the functioning of the $\mathrm{OE}$ including a change of odorant detection through ATP release from neighboring cells (Bryche et al. 2019a). The recent surge of anosmia linked to the COVID-19 pandemic has increased the number of studies of the importance of the immune system for the OE (Torabi et al. 2020).
At the interface of the environment and the nervous system, the OE constitutes a privileged pathway for harmful environmental agents including viruses, bacteria, amoebae, and environmental chemicals towards the central nervous system (Dando et al. 2014). This neuro-immune interface has been characterized in various vertebrates including salamanders (Getchell and Getchell 1991), humans (Mellert et al. 1992), chickens (Ohshima and Hiramatsu 2000), rodents (Imamura and Hasegawa-Ishii 2016), and teleost fishes (Yu et al. 2018). The OE is subject to immune cell infiltration and immune modulations, partly from a nasal associated lymphoid tissue (NALT) localized at the base of the nasal cavity (Tacchi et al. 2014) and described in most vertebrates (Tacchi et al. 2014). Cells of the OE synthetizes and secretes various immune and antimicrobial factors including mucosal immunoglobulins (Getchell and Getchell 1991) and chemokines (Ruitenberg et al. 2008). Moreover, the specific composition of the mucus covering the OE, which has not been fully characterized despite advances in proteomics approaches, appears to be central in the innate immune protection of the OE (Yoshikawa et al. 2018). Beyond the obvious role of the immune system in pathological situations, it appears also to be crucial in maintaining OE homeostasis and OSN activity, as indicated by a growing body of literature (Doty and Kamath 2014; Chen et al. 2019; Rustenhoven and Kipnis 2019).

We will first present studies showing changes of OSN activity linked to the immune system (in healthy or pathological conditions) before discussing possible mechanisms.

\section{OSN activity and inflammation: roles of the immune system}

There is a large body of literature linking nasal inflammation, damage to the $\mathrm{OE}$, and olfactory disorders. In humans, chronic rhinosinusitis is one of the most common causes of olfactory loss (Gudis and Soler 2016). Several studies found correlations between olfactory cleft inflammatory cytokines/chemokines and olfactory performance in chronic rhinosinusitis patients (Yoo et al. 2019). In these patients, altered levels of proinflammatory cytokines including tumor necrosis factor-alpha (TNF- $\alpha$ ) and interleukin-6 (IL-6) in olfactory cleft mucus are associated with reduced olfactory identification scores (Wu et al. 2018). Additionally, clinical studies indicate that immunodeficiencies (Magliulo et al. 2019) or uncontrolled activation of immune cells occurring in autoimmune diseases (Shin et al. 2019) can alter the capacity to smell, typically at the onset of disease. There are also olfactory disorders associated with immunomodulatory therapies, such as interferon- $\alpha$ treatment used to treat patients with hepatitis (Maruyama et al. 1998; Kraus and Vitezic 2000; Mayet 2007). The improvement of olfactory capacities through anti-inflammatory treatments like 
glucocorticoid also testifies to the impact of inflammatory state on olfactory capacities (reviewed in Beecher et al. 2018).

To study more specifically the effect of cytokines on the olfactory system, and to explore inflammation-associated olfactory loss in vivo, a transgenic mouse with inducible olfactory inflammation was developed (Lane et al. 2010). This model, which mimics clinical aspects of human rhinosinusitis-associated olfactory loss, allows induction of $\mathrm{OE}$ cytokines expression, such as TNF- $\alpha$.

Chronic inflammation induced by prolonged TNF- $\alpha$ expression causes an infiltration of inflammatory cells in the lamina propria (mainly macrophages), a thinning of the olfactory neuronal layer, and a progressive loss of olfactory function. These changes are accompanied by neuronal apoptosis and suppression of normal olfactory regeneration along with a decrease of $\sim 60 \%$ in the response to odorant stimulation as recorded by EOGs (Lane et al. 2010; Turner et al. 2010). Further works with this model have highlighted the importance of TNF receptors of type II in such processes (Pozharskaya et al. 2013).

A functional immune system also appears necessary to maintain OE function. In 2015, Rattazi et al., identified impaired sense of smell and altered olfactory system in RAG-1-/- (recombination-activating gene 1) immunodeficient mice. RAG-1 is involved with RAG-2 in the rearrangement and recombination of the genes encoding immunoglobulin and $\mathrm{T}$ cell receptor molecules (Rattazzi et al. 2015). These two genes are therefore central to immune development. The OE of RAG-1-/- immunodeficient mice is atrophied and glomeruli in the $\mathrm{OB}$ are disorganized. These changes are correlated with diminished performance in olfactory tests (buried cookie test reviewed in Zou et al. 2015). Intriguingly, these defects only appear in adults and are not related to impaired development of the olfactory system. Among other hypotheses, the authors proposed that the NALT could be impaired in RAG-1-/- mice as it specifically develops after birth (Gänger and Schindowski 2018). NALT has been shown to be important for the release of factors regulating OE proliferation, differentiation, and maturation (Yu et al. 2018) - for review see Sepahi and Salinas 2016). Although these results contrast with a study performed in zebrafish where depletion of RAG-1 did not impact the development of the olfactory system (Feng et al. 2005), they do show the importance of the immune system for the maintenance of the integrity of olfactory function.

\section{Proposed mechanisms for the modulation of vertebrate olfactory epithelium functionality by the immune system}

Although there is an undeniable link between immune component inflammation and altered olfactory capacity, there is little evidence of a direct connection between these two phenomena and mechanistic data are lacking. Moreover, interactions between immune cells and the $\mathrm{OE}$ are mostly studied in pathological and multifactorial contexts and it is therefore difficult to uncover the specific mechanisms linking the two systems. Few hypotheses have been published; some of the main ones are presented below.

\section{Linking olfactory sensory neuron transduction to immune system components: implication of perireceptor events}

Over the last decade, a growing body of literature has shown the critical modulatory role of perireceptor events in the olfactory process (Heydel et al. 2019). These events rely on two main groups of proteins: odorant-binding proteins (OBPs) and enzymes surrounding the OR which are thought to be involved in odorant availability and/or olfactory signal termination (Robert-Hazotte et al. 2019; Heydel et al. 2019; Schwartz et al. 2020). Thus, any inflammatory process impacting mucus secretion, mucus composition, or the expression of compounds related to perireceptor events, including bioavailability of odorant-metabolizing enzymes (Morgan et al. 2008; Ijichi et al. 2019; Stanke-Labesque et al. 2020), may result in modulation of odorant detection (Fukuda et al. 2008; Robert-Hazotte et al. 2019).

OBPs are among the most expressed proteins in mucus (Kuntová et al. 2018). Their expression is affected by the inflammatory state in the nasal cavity (Yoshikawa et al. 2018). Our group found that OBP expression level is upregulated in axenic mice (François et al. 2016) and that viral infection of the OE also alters OBP expression in conventionally bred mice (Bryche et al. 2019b). Interestingly, a recent study highlights a relationship between the olfactory performance and the rs 2590498 polymorphism of the OBPIIa gene (Sollai et al. 2019), which encodes the only OBP found in the OE of humans. This suggests a potential link between OBPIIa function and olfactory detection. Additionally, recent data suggest that OBPs may also act as antimicrobial components against pathogenic microorganisms (Bianchi et al. 2019). The dual role of OBPs in olfaction and immunity is also highlighted by a study indicating that OBPs may modulate neutrophil recruitment through binding to macrophage-derived inflammatory mediators in the upper airway (Mitchell et al. 2011).

\section{Linking olfactory sensory neuron transduction to immune system components: ionic homeostasis in the mucus}

Inflammation can also modify the ionic concentration in the mucus which is essential for an efficient olfactory transduction. As an example, chronic inflammation mediated by nasal instillation of a fungal protein extract of $A$. fumigatus in mice, led to a significant decrease in sodium concentration 
and a marked increase in potassium concentration in the mucus (Selvaraj et al. 2012). These changes will impact OSN activity as olfactory transduction is based on cyclic nucleotide gated channels localized in their cilia (Li et al. 2016). Indeed, cyclic nucleotide gated channels mediate sensory transduction by conducting cationic currents carried primarily by sodium and calcium ions (Pifferi et al. 2006). Additionally, alteration of the ionic olfactory micro-environment by nasal irrigation (i.e., a sinus instillation with solutions of various ionic concentrations) in healthy patients lead to a significant olfactory threshold shift assessed by Sniffin' Sticks test (a psychophysical test that allows assessment of the patient's olfactory performance by means of 3 subtests: threshold test, identification test, and discrimination test) (see technical note-Rumeau et al. 2016).

These results were confirmed later by another group, which clearly demonstrates that deviations of both sodium and potassium levels from their homeostatic values can result in olfactory threshold elevations and therefore explain, at least in part, the olfactory dysfunction associated with chronic inflammation (Lam et al. 2015).

Using an induced olfactory inflammation model, Lane et al. (2010) found that OSNs respond to TNF- $\alpha$ with a $\mathrm{Ca}^{2+}$ influx, which may explain the reduced EOG responses. Lane and collaborators propose that the chronic presence of proinflammatory cytokines could reduce EOG responses by establishing a desensitized state that leads to reduced neuronal firing (Lane et al. 2010). Such an importance for a finely regulated spatial and temporal dynamics of calcium influx in the modulation of olfactory transduction has been confirmed later (Reisert and Reingruber 2019). Our group recently focused on IL-17C, an interleukin playing a crucial role in mucosal areas and whose neuromodulatory properties are well-described in the peripheral nervous system (Peng et al. 2017). By performing calcium imaging on olfactory mucosa slices, we found that IL-17C modulates the calcium levels in the OE within seconds of application (Bryche et al. 2019a). This modulation appears to be indirect via the release of ATP from neighbouring cells, which inhibit calcium responses upon stimulation by odors (Rotermund et al. 2019). Indeed, IL-17C induced calcium responses were effectively blocked by purinergic receptor antagonists supporting an involvement of purinergic signalling. Additionally, our EOG results showed that IL-17C decreases the amplitude of odorinduced responses in the $\mathrm{OE}$, accordingly to the purinergic implication hypothesis. Overall, these results are consistent with an IL-17C-induced ATP release in mice, leading to calcium variation and a subsequent decrease in EOG responses.

\section{Olfactory epithelium cell dynamics: functional switch of cells from neuro-regeneration to immune defence}

During the past decade, immune cells and cytokines have been shown to play pivotal roles in regulation of apoptosis and neurogenesis in the $\mathrm{OE}$, which is a unique self-renewing tissue. In addition to the review of Imamura and HasegawaIshii (2016) exploring this topic in murine species, Borders et al. showed in mice that activated macrophages regulate neural progenitor cell proliferation, differentiation, maturation, and survival of OSN through the modulation of the expression of several genes (Borders et al. 2007a, b). Data obtained with the induced olfactory inflammation model suggest that there are two distinct phases of the olfactory deficit related to inflammation: an initial phase of physiological desensitization, followed by a cellular loss that results in a profound elimination of sensory activity (Lane et al. 2010). This model has been refined recently with the work of Chen et al. (2019). In their study, they describe the inflammation-induced switching of olfactory stem cells from a regenerative phenotype to one participating in immune defense. Indeed, acute olfactory inflammation causes an initial loss of OSNs which greatly impacts olfactory function. It results in the proliferation of previously quiescent basal cells which can differentiate to restore mature OSNs. Contrastingly, during chronic inflammation, NF- $\mathrm{KB}$ (nuclear factor kappa-light-chain-enhancer of activated B cells) signalling in basal cells is activated. This large family of inducible transcription factors, which regulates a large array of genes involved in different processes of the inflammatory and immune responses (Liu et al. 2017) triggers a functional switch from a regenerative phenotype to a quiescent one. This switch allows the recruitment and the regulation of peripheral immune populations through chemokine secretion and therefore prioritizes pathogen removal (Fig. 3 and Chen et al. 2019; Rustenhoven and Kipnis 2019). Such chronic or severe inflammation could result in impaired regeneration of the $\mathrm{OE}$ as well as long lasting if not permanent anosmia.

\section{Concluding remarks on neuroimmune interactions}

Several areas of research remain to be explored to improve our understanding of the role of the immune system within the OE. These include:

1. to identify precisely resident immune cells within the $\mathrm{OE}$ and their relative involvement in the OE homeostasis,

2. to determine accurately how the immune response in the nasal cavity affects OSNs.

Finally, the position of the $\mathrm{OE}$ at the interface between the environment and the central nervous system also raises questions about the relative contribution of nasal inflammation to the pathogenesis of neurodegenerative disorders (Imamura and Hasegawa-Ishii 2016). This is particularly well illustrated by the hypothesis of Parkinson disease originating from viral infection of the OM (Doty 2008). New 


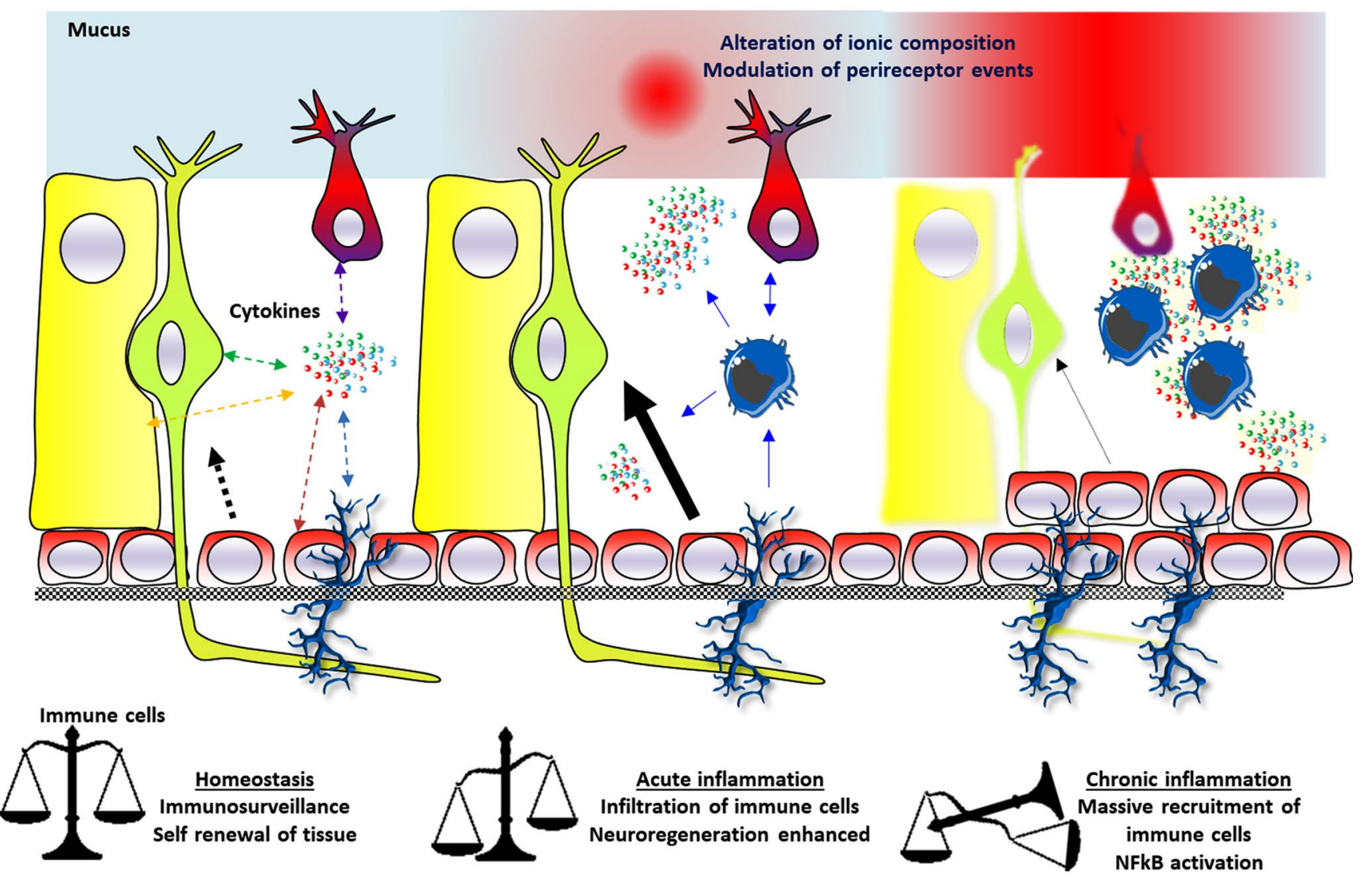

Fig. 3 Overview of the importance of the immune system in the olfactory epithelium. Cells of the olfactory epithelium (OE) are capable of synthesizing and releasing cytokines for autocrine or paracrine actions. In a homeostasis situation, proliferative basal cells allow for self-renewal of the whole tissue, including generation of olfactory sensory neurons which maintain appropriate odor-sensing capabilities despite the presence of pathogens and xenobiotics in the mucus. Immune cells exert immunosurveillance. During an acute infection, neuronal death is observed, which is limited by the rapid OE renewal,

insights into the role of cytokines and immune cells in causing human olfactory dysfunction will potentially lead to new and more efficient therapies.

\section{Conclusion}

In this review, we tried to provide an overall albeit nonexhaustive view of the changes in olfactory signals in the OE. Previous studies on the expression of modulator receptors in the OE clearly showed that most are also expressed in the $\mathrm{OB}$ raising the question of a potential redundancy of modulation at these two levels of olfactory processing. There are several future research directions:

1. Similarly to many other research fields, we need to consider the use of diverse species in research before linked to immune cell infiltration (regenerative state). Immune components may alter mucus secretion and composition, modulate ionic balance and perireceptor events and therefore change the olfactory signal. Conversely, with chronic inflammation, there is a switch from a regenerative phenotype of basal cells to proliferation without differentiation in $\mathrm{OE}$ cells. This switch prioritizes pathogen removal involving massive immune cell recruitment and activation of nuclear factor- $\mathrm{kB}(\mathrm{NFkB})$ in basal cells

generalizing the importance of a modulation that is often studied solely in mice. Indeed, Fig. 1 clearly demonstrates the over-representation of mice studies, even if we tried to include as many relevant studies as possible from other vertebrates.

2. The development of genetically engineered mice expressing reporter genes in a subpopulation of OSNs has drawn much attention to a limited number of OR genes (mainly I7 and m71) and recent transcriptomic studies have demonstrated that the OSN modulation is variable according to the expressed receptor and mouse strain (Ibarra-Soria et al. 2017). Thus, caution must be applied before generalizing the observed modulation of OSN activity.

3. Due to the complexity of understanding the role of a single modulator, most are studied alone at nonphysiological concentrations and in ex vivo conditions. 
Antagonism or synergy between different messengers certainly exists. For example, the perception of odors can be influenced by stress and the inner emotional state of the animal (Raynaud et al. 2015; Bombail 2019; Meunier et al. 2020). Many experiments using anesthesia, animal manipulation, and intranasal instillation may induce stress and thus interact with the studied modulator. Exploring such interactions between modulators will be a future challenge to understand olfactory modulation at its higher level of integration, as demonstrated for ATP interactions with many other messengers such as NPY (Jia and Hegg 2010) or IL-17C (Bryche et al. 2019a). As ATP production is related to other modulators, it also raises the more general question of the nature of the signal triggering this production. Understanding the release mechanism behind these modulators and identifying cells releasing such compounds constitute a further step in the understanding of these messenger actions.

Finally, the main action of modulators may have been overlooked. For instance, the olfactory marker protein (OMP) has been identified more than 40 years ago (Hartman and Margolis 1975). OMP has been suspected for a long time to play a very important role in OSN maturation and OSN plasticity notably induced by external stimuli (Lee et al. 2011; Kass et al. 2013a). Astonishingly, a very recent study demonstrated that OMP was a cAMP buffer which was completely unexpected (Nakashima et al. 2020). Similarly, future studies may reveal previously unknown roles for OSN response modulators.

Acknowledgements We would like to thank Dr Birte L Nielsen and Dr Vincent Bombail for useful comments on earlier versions of this manuscript. Constructive criticism from the anonymous reviewers was greatly appreciated.

\section{Declarations}

Ethical approval On behalf of all authors, the corresponding author states that there is no conflict of interest. This review was written without specific funding, and was performed using previously published results, without additional experimentation involving human participants or animals.

\section{References}

Abraham NM, Vincis R, Lagier S et al (2014) Long term functional plasticity of sensory inputs mediated by olfactory learning. Elife 3:e02109. https://doi.org/10.7554/eLife.02109

Acevedo C, Blanchard K, Bacigalupo J, Vergara C (2019) Possible ATP trafficking by ATP-shuttles in the olfactory cilia and glucose transfer across the olfactory mucosa. FEBS Lett 593:601-610. https://doi.org/10.1002/1873-3468.13346
Baly C, Aioun J, Badonnel K et al (2007) Leptin and its receptors are present in the rat olfactory mucosa and modulated by the nutritional status. Brain Res 1129:130-141. https://doi.org/10.1016/j. brainres.2006.10.030

Baxter BD, Larson ED, Feinstein P, et al (2020) Transcriptional profiling reveals TRPM5-expressing cells involved in viral infection in the olfactory epithelium. bioRxiv. https://doi.org/10.1101/2020. 05.14.096016

Beecher K, St John JA, Chehrehasa F (2018) Factors that modulate olfactory dysfunction. Neural Regen Res 13:1151-1155. https:// doi.org/10.4103/1673-5374.235018

Berditchevskaia A, Cazé RD, Schultz SR (2016) Performance in a GO/ NOGO perceptual task reflects a balance between impulsive and instrumental components of behaviour. Sci Rep 7(6):27389. https:// doi.org/10.1038/srep27389.PMID:27272438;PMCID:PMC4895381

Bianchi F, Flisi S, Careri M et al (2019) Vertebrate odorant binding proteins as antimicrobial humoral components of innate immunity for pathogenic microorganisms. PLoS One 14:e0213545. https://doi.org/10.1371/journal.pone.0213545

Bombail V (2019) Perception and emotions: on the relationships between stress and olfaction. Appl Anim Behav Sci 212:98-108. https://doi.org/10.1016/j.applanim.2018.12.013

Borders AS, Getchell ML, Etscheidt JT et al (2007a) Macrophage depletion in the murine olfactory epithelium leads to increased neuronal death and decreased neurogenesis. J Comp Neurol 501:206-218. https://doi.org/10.1002/cne.21252

Borders AS, Hersh MA, Getchell ML et al (2007b) Macrophagemediated neuroprotection and neurogenesis in the olfactory epithelium. Physiol Genomics 31:531-543. https://doi.org/10. 1152/physiolgenomics.00008.2007

Bouvet JF, Delaleu JC, Holley A (1988) The activity of olfactory receptor cells is affected by acetylcholine and substance P. Neurosci Res 5:214-223. https://doi.org/10.1016/01680102(88)90050-8

Breunig E, Manzini I, Piscitelli F et al (2010) The endocannabinoid 2-arachidonoyl-glycerol controls odor sensitivity in larvae of Xenopus laevis. J Neurosci 30:8965-8973. https://doi.org/10. 1523/JNEUROSCI.4030-09.2010

Brünner YF, Benedict C, Freiherr J (2013) Intranasal insulin reduces olfactory sensitivity in normosmic humans. J Clin Endocrinol Metab 98:E1626-1630. https://doi.org/10.1210/jc.2013-2061

Bryche B, Dewaele A, Saint-Albin A et al (2019a) IL-17c is involved in olfactory mucosa responses to Poly(I:C) mimicking virus presence. Brain Behav Immun 79:274-283. https://doi.org/10.1016/j. bbi.2019.02.012

Bryche B, Frétaud M, Saint-Albin Deliot A, et al (2019b) Respiratory syncytial virus tropism for olfactory sensory neurons in mice. J Neurochem e14936. https://doi.org/10.1111/jnc.14936

Bryche B, Le Bourhis M, Congar P et al (2019) Endothelin impacts on olfactory processing in rats. Behav Brain Res 362:1-6. https:// doi.org/10.1016/j.bbr.2018.12.048

Bryche B, St Albin A, Murri S et al (2020) Massive transient damage of the olfactory epithelium associated with infection of sustentacular cells by SARS-CoV-2 in golden Syrian hamsters. Brain Behav Immun 89:579-586. https://doi.org/10.1016/j.bbi.2020.06.032

Cadiou H, Aoudé I, Tazir B et al (2014) Postnatal odorant exposure induces peripheral olfactory plasticity at the cellular level. J Neurosci 34:4857-4870. https://doi.org/10.1523/JNEUROSCI. 0688-13.2014

Caillol M, Aïoun J, Baly C et al (2003) Localization of orexins and their receptors in the rat olfactory system: possible modulation of olfactory perception by a neuropeptide synthetized centrally or locally. Brain Res 960:48-61. https://doi.org/10.1016/s00068993(02)03755-1

Chen M, Reed RR, Lane AP (2019) Chronic inflammation directs an olfactory stem cell functional switch from neuroregeneration to 
immune defense. Cell Stem Cell 25:501-513.e5. https://doi.org/ 10.1016/j.stem.2019.08.011

Colquitt BM, Markenscoff-Papadimitriou E, Duffié R, Lomvardas S (2014) Dnmt3a regulates global gene expression in olfactory sensory neurons and enables odorant-induced transcription. Neuron 83:823-838. https://doi.org/10.1016/j.neuron.2014.07.013

Coppola DM (2012) Studies of olfactory system neural plasticity: the contribution of the unilateral naris occlusion technique. Neural Plast 2012:351752. https://doi.org/10.1155/2012/351752

Czesnik D, Kuduz J, Schild D, Manzini I (2006) ATP activates both receptor and sustentacular supporting cells in the olfactory epithelium of Xenopus laevis tadpoles. Eur J Neurosci 23:119-128. https://doi.org/10.1111/j.1460-9568.2005.04533.x

Czesnik D, Schild D, Kuduz J, Manzini I (2007) Cannabinoid action in the olfactory epithelium. Proc Natl Acad Sci U S A 104:29672972. https://doi.org/10.1073/pnas.0609067104

Dando SJ, Mackay-Sim A, Norton R et al (2014) Pathogens penetrating the central nervous system: infection pathways and the cellular and molecular mechanisms of invasion. Clin Microbiol Rev 27:691-726. https://doi.org/10.1128/CMR.00118-13

Demirler MC, Sakizli U, Bali B et al (2020) Purinergic signalling selectively modulates maintenance but not repair neurogenesis in the zebrafish olfactory epithelium. FEBS J 287:2699-2722. https:// doi.org/10.1111/febs. 15170

Dewaele A, Persuy MA, Badonnel K et al (2018) Chronic perinatal odour exposure with heptaldehyde affects odour sensitivity and olfactory system homeostasis in preweaning mice. Behav Brain Res 347:414-424. https://doi.org/10.1016/j.bbr.2018.02.026

Dias BG, Ressler KJ (2014) Parental olfactory experience influences behavior and neural structure in subsequent generations. Nat Neurosci 17:89-96. https://doi.org/10.1038/nn.3594

Doty RL (2008) The olfactory vector hypothesis of neurodegenerative disease: is it viable? Ann Neurol 63:7-15. https://doi.org/ 10.1002/ana.21327

Doty RL, Kamath V (2014) The influences of age on olfaction: a review. Front Psychol 5:20. https://doi.org/10.3389/fpsyg.2014. 00020

Doyle KL, Cunha C, Hort Y et al (2018) Role of neuropeptide Y (NPY) in the differentiation of Trpm-5-positive olfactory microvillar cells. Neuropeptides 68:90-98. https://doi.org/10.1016/j.npep. 2018.02.007

Elsaesser R, Montani G, Tirindelli R, Paysan J (2005) Phosphatidylinositide signalling proteins in a novel class of sensory cells in the mammalian olfactory epithelium. Eur J Neurosci 21:26922700. https://doi.org/10.1111/j.1460-9568.2005.04108.x

Elsaesser R, Paysan J (2007) The sense of smell, its signalling pathways, and the dichotomy of cilia and microvilli in olfactory sensory cells. BMC Neurosci 8(Suppl 3):S1. https://doi.org/10.1186/ 1471-2202-8-S3-S1

Farbman AI, Brunjes PC, Rentfro L et al (1988) The effect of unilateral naris occlusion on cell dynamics in the developing rat olfactory epithelium. J Neurosci 8:3290-3295

Feng B, Bulchand S, Yaksi E et al (2005) The recombination activation gene $1(\operatorname{Rag} 1)$ is expressed in a subset of zebrafish olfactory neurons but is not essential for axon targeting or amino acid detection. BMC Neurosci 6:46. https://doi.org/10.1186/ 1471-2202-6-46

Fitzwater E, Coppola DM (2021) Olfactory Deprivation and Enrichment: An Identity of Opposites? Chem Senses 46. https://doi.org/ 10.1093/chemse/bjaa071

François A, Grebert D, Rhimi M, et al (2016) Olfactory epithelium changes in germfree mice. Sci Rep 6. https://doi.org/10.1038/ srep24687

François A, Laziz I, Rimbaud S et al (2013) Early survival factor deprivation in the olfactory epithelium enhances activity-driven survival. Front Cell Neurosci 7:271. https://doi.org/10.3389/ fncel.2013.00271

Frontera JL, Cervino AS, Jungblut LD, Paz DA (2015) Brain-derived neurotrophic factor (BDNF) expression in normal and regenerating olfactory epithelium of Xenopus laevis. Ann Anat 198:4148. https://doi.org/10.1016/j.aanat.2014.10.010

Fu Z, Ogura T, Luo W, Lin W (2018) ATP and odor mixture activate TRPM5-expressing microvillous cells and potentially induce acetylcholine release to enhance supporting cell endocytosis in mouse main olfactory epithelium. Front Cell Neurosci 12:71. https://doi.org/10.3389/fncel.2018.00071

Fukuda N, Shirasu M, Sato K et al (2008) Decreased olfactory mucus secretion and nasal abnormality in mice lacking type 2 and type 3 IP3 receptors. Eur J Neurosci 27:2665-2675. https://doi.org/ 10.1111/j.1460-9568.2008.06240.x

Gänger S, Schindowski K (2018) Tailoring Formulations for Intranasal Nose-to-Brain Delivery: A Review on Architecture, PhysicoChemical Characteristics and Mucociliary Clearance of the Nasal Olfactory Mucosa. Pharmaceutics 10. https://doi.org/10.3390/ pharmaceutics10030116

Genovese F, Tizzano M (2018) Microvillous cells in the olfactory epithelium express elements of the solitary chemosensory cell transduction signaling cascade. PLoS One 13:e202754. https:// doi.org/10.1371/journal.pone.0202754

Gerlach G, Tietje K, Biechl D, et al (2019) Behavioural and neuronal basis of olfactory imprinting and kin recognition in larval fish. $\mathrm{J}$ Exp Biol 222. https://doi.org/10.1242/jeb.189746

Getchell ML, Getchell TV (1991) Immunohistochemical localization of components of the immune barrier in the olfactory mucosae of salamanders and rats. Anat Rec 231:358-374. https://doi.org/ 10.1002/ar.1092310310

Gudden, (1870) Experimentaluntersuchungen über das peripherische und centrale Nervensystem. Archiv f Psychiatrie 2:693-723. https://doi.org/10.1007/BF02046772

Gudis DA, Soler ZM (2016) Chronic rhinosinusitis-related smell loss: medical and surgical treatment efficacy. Curr Otorhinolaryngol Rep 4:142-147. https://doi.org/10.1007/s40136-016-0114-4

Hansel DE, Eipper BA, Ronnett GV (2001) Neuropeptide Y functions as a neuroproliferative factor. Nature 410:940-944. https://doi. org/10.1038/35073601

Hansen A, Finger TE (2008) Is TrpM5 a reliable marker for chemosensory cells? Multiple types of microvillous cells in the main olfactory epithelium of mice. BMC Neurosci 9:115. https://doi. org/10.1186/1471-2202-9-115

Harden MV, Newton LA, Lloyd RC, Whitlock KE (2006) Olfactory imprinting is correlated with changes in gene expression in the olfactory epithelia of the zebrafish. J Neurobiol 66:1452-1466. https://doi.org/10.1002/neu.20328

Hartman BK, Margolis FL (1975) Immunofluorescence localization of the olfactory marker protein. Brain Res 96:176-180. https://doi. org/10.1016/0006-8993(75)90593-4

Hassenklöver T, Schwartz P, Schild D, Manzini I (2009) Purinergic signaling regulates cell proliferation of olfactory epithelium progenitors. Stem Cells 27:2022-2031. https://doi.org/10.1002/ stem. 126

Hayden S, Teeling EC (2014) The molecular biology of vertebrate olfaction. Anat Rec (Hoboken) 297:2216-2226. https://doi.org/ 10.1002/ar.23031

Hayoz S, Jia C, Hegg C (2012) Mechanisms of constitutive and ATPevoked ATP release in neonatal mouse olfactory epithelium. BMC Neurosci 13:53. https://doi.org/10.1186/1471-2202-13-53

He J, Tian H, Lee AC, Ma M (2012) Postnatal experience modulates functional properties of mouse olfactory sensory neurons. Eur J Neurosci 36:2452-2460. https://doi.org/10.1111/j.1460-9568. 2012.08170.x 
Hegg CC, Au E, Roskams AJ, Lucero MT (2003) PACAP is present in the olfactory system and evokes calcium transients in olfactory receptor neurons. J Neurophysiol 90:2711-2719. https://doi.org/ 10.1152/jn.00288.2003

Hegg CC, Irwin M, Lucero MT (2009) Calcium store-mediated signaling in sustentacular cells of the mouse olfactory epithelium. Glia 57:634-644. https://doi.org/10.1002/glia.20792

Hegg CC, Jia C, Chick WS et al (2010) Microvillous cells expressing IP3 receptor type 3 in the olfactory epithelium of mice. Eur J Neurosci 32:1632-1645. https://doi.org/10.1111/j.1460-9568. 2010.07449.x

Henriques T, Agostinelli E, Hernandez-Clavijo A et al (2019) TMEM16A calcium-activated chloride currents in supporting cells of the mouse olfactory epithelium. J Gen Physiol 151:954966. https://doi.org/10.1085/jgp.201812310

Herz RS (1998) Are odors the best cues to memory? A cross-modal comparison of associative memory stimuli. Ann N Y Acad Sci 855:670-674. https://doi.org/10.1111/j.1749-6632.1998. tb10643.x

Heydel JM, Faure P, Neiers F (2019) Nasal odorant metabolism: enzymes, activity and function in olfaction. Drug Metab Rev 1-45. https://doi.org/10.1080/03602532.2019.1632890

Hollyday M, Hamburger V, Farris JM (1977) Localization of motor neuron pools supplying identified muscles in normal and supernumerary legs of chick embryo. Proc Natl Acad Sci U S A 74:3582-3586. https://doi.org/10.1073/pnas.74.8.3582

Housley GD, Bringmann A, Reichenbach A (2009) Purinergic signaling in special senses. Trends Neurosci 32:128-141. https://doi. org/10.1016/j.tins.2009.01.001

Hummel T, Stupka G, Haehner A, Poletti SC (2018) Olfactory training changes electrophysiological responses at the level of the olfactory epithelium. Rhinology 56:330-335. https://doi.org/10. 4193/Rhin 17.163

Hutch CR, Hillard CJ, Jia C, Hegg CC (2015) An endocannabinoid system is present in the mouse olfactory epithelium but does not modulate olfaction. Neuroscience 300:539-553. https://doi.org/ 10.1016/j.neuroscience.2015.05.056

Ibarra-Soria X, Nakahara TS, Lilue J, et al (2017) Variation in olfactory neuron repertoires is genetically controlled and environmentally modulated. Elife 6. https://doi.org/10.7554/eLife.21476

Ijichi C, Wakabayashi H, Sugiyama S et al (2019) Metabolism of odorant molecules in human nasal/oral cavity affects the odorant perception. Chem Senses 44:465-481. https://doi.org/10.1093/ chemse/bjz041

Imamura F, Hasegawa-Ishii S (2016) Environmental toxicants-induced immune responses in the olfactory mucosa. Front Immunol 7:475. https://doi.org/10.3389/fimmu.2016.00475

Jia C, Hayoz S, Hutch CR et al (2013) An IP3R3- and NPY-expressing microvillous cell mediates tissue homeostasis and regeneration in the mouse olfactory epithelium. PLoS One 8:e58668. https:// doi.org/10.1371/journal.pone.0058668

Jia C, Hegg CC (2010) NPY mediates ATP-induced neuroproliferation in adult mouse olfactory epithelium. Neurobiol Dis 38:405-413. https://doi.org/10.1016/j.nbd.2010.02.013

Jia C, Hegg CC (2012) Neuropeptide Y and extracellular signal-regulated kinase mediate injury-induced neuroregeneration in mouse olfactory epithelium. Mol Cell Neurosci 49:158-170. https://doi. org/10.1016/j.mcn.2011.11.004

Jiang Y, Matsunami H (2015) Mammalian odorant receptors: functional evolution and variation. Curr Opin Neurobiol 34:54-60. https://doi.org/10.1016/j.conb.2015.01.014

Jones SV, Choi DC, Davis M, Ressler KJ (2008) Learning-dependent structural plasticity in the adult olfactory pathway. J Neurosci 28:13106-13111. https://doi.org/10.1523/JNEUROSCI.446508.2008
Kass MD, Moberly AH, McGann JP (2013) Spatiotemporal alterations in primary odorant representations in olfactory marker protein knockout mice. PLoS One 8:e61431. https://doi.org/10.1371/ journal.pone.0061431

Kass MD, Rosenthal MC, Pottackal J, McGann JP (2013) Fear learning enhances neural responses to threat-predictive sensory stimuli. Science 342:1389-1392. https://doi.org/10.1126/science. 1244916

Kerr MA, Belluscio L (2006) Olfactory experience accelerates glomerular refinement in the mammalian olfactory bulb. Nat Neurosci 9:484-486. https://doi.org/10.1038/nn1673

Kraus I, Vitezic D (2000) Anosmia induced with alpha interferon in a patient with chronic hepatitis C. Int J Clin Pharmacol Ther 38:360-361. https://doi.org/10.5414/cpp38360

Kuntová B, Stopková R, Stopka P (2018) Transcriptomic and Proteomic Profiling Revealed High Proportions of Odorant Binding and Antimicrobial Defense Proteins in Olfactory Tissues of the House Mouse. Front Genet 9. https://doi.org/10.3389/fgene. 2018.00026

Lacroix MC, Badonnel K, Meunier N et al (2008) Expression of insulin system in the olfactory epithelium: first approaches to its role and regulation. J Neuroendocrinol 20:1176-1190. https://doi.org/10. $1111 / \mathrm{j} .1365-2826.2008 .01777 . x$

Lam K, Conley DB, Liu K et al (2015) Effect of ionic compositions in nasal irrigations on human olfactory thresholds. Laryngoscope 125:E50-56. https://doi.org/10.1002/lary.24941

Lane AP, Turner J, May L, Reed R (2010) A genetic model of chronic rhinosinusitis-associated olfactory inflammation reveals reversible functional impairment and dramatic neuroepithelial reorganization. J Neurosci 30:2324-2329. https://doi.org/10.1523/ JNEUROSCI.4507-09.2010

Le Bon SD, Horoi M (2020) Is anosmia the price to pay in an immune-induced scorched-earth policy against COVID-19? Med Hypotheses 143:109881. https://doi.org/10.1016/j.mehy. 2020.109881

Le Bourhis M, Rimbaud S, Grebert D et al (2014) Endothelin uncouples gap junctions in sustentacular cells and olfactory ensheathing cells of the olfactory mucosa. Eur J Neurosci 40:2878-2887. https://doi.org/10.1111/ejn.12665

Lee AC, He J, Ma M (2011) Olfactory marker protein is critical for functional maturation of olfactory sensory neurons and development of mother preference. J Neurosci 31:2974-2982. https://doi. org/10.1523/JNEUROSCI.5067-10.2011

Li RC, Ben-Chaim Y, Yau KW, Lin CC (2016) Cyclic-nucleotide-gated cation current and $\mathrm{Ca} 2+$-activated $\mathrm{Cl}$ current elicited by odorant in vertebrate olfactory receptor neurons. Proc Natl Acad Sci USA 113:11078-11087. https://doi.org/10.1073/pnas.1613891113

Li YR, Matsunami H (2011) Activation state of the M3 muscarinic acetylcholine receptor modulates mammalian odorant receptor signaling. Sci Signal 4:ra1. https://doi.org/10.1126/scisignal.2001230

Liang F (2020) Sustentacular cell enwrapment of olfactory receptor neuronal dendrites: an update genes (Basel) 11. https://doi.org/ 10.3390/genes11050493

Lin W, Ezekwe EAD, Zhao Z et al (2008) TRPM5-expressing microvillous cells in the main olfactory epithelium. BMC Neurosci 9:114. https://doi.org/10.1186/1471-2202-9-114

Liu T, Zhang L, Joo D, Sun SC (2017) NF-kB signaling in inflammation. Signal Transduct Target Ther 2 https://doi.org/10.1038/sigtrans.2017.23

Loch D, Breer H, Strotmann J (2015) Endocrine modulation of olfactory responsiveness: effects of the orexigenic hormone ghrelin. Chem Senses 40:469-479. https://doi.org/10.1093/chemse/ bjv028

Loch D, Heidel C, Breer H, Strotmann J (2013) Adiponectin enhances the responsiveness of the olfactory system. PLoS One 8:e75716. https://doi.org/10.1371/journal.pone.0075716 
Logan DW, Brunet LJ, Webb WR et al (2012) Learned recognition of maternal signature odors mediates the first suckling episode in mice. Curr Biol 22:1998-2007. https://doi.org/10.1016/j.cub. 2012.08.041

Lucero MT (2013) Peripheral modulation of smell: fact or fiction? Semin Cell Dev Biol 24:58-70. https://doi.org/10.1016/j.semcdb. 2012.09.001

Magliulo G, Iannella G, Ciofalo A et al (2019) The olfactory function in patients with common variable immunodeficiency. Eur Ann Otorhinolaryngol Head Neck Dis 136:429-434. https://doi.org/ 10.1016/j.anorl.2018.02.003

Maruyama S, Hirayama C, Kadowaki Y et al (1998) Interferon-induced anosmia in a patient with chronic hepatitis C. Am J Gastroenterol 93:122-123. https://doi.org/10.1111/j.1572-0241.1998.122_c.x

Masaki T (2004) Historical review: endothelin. Trends Pharmacol Sci 25:219-224. https://doi.org/10.1016/j.tips.2004.02.008

Mayet AY (2007) Loss of smell (anosmia) and taste (ageusia) in a patient treated with pegylated interferon alfa and ribavirin. Curr Ther Res Clin Exp 68:271-277. https://doi.org/10.1016/j.curtheres.2007.08. 006

McGann JP (2015) Associative learning and sensory neuroplasticity: how does it happen and what is it good for? Learn Mem 22:567576. https://doi.org/10.1101/lm.039636.115

Mellert TK, Getchell ML, Sparks L, Getchell TV (1992) Characterization of the immune barrier in human olfactory mucosa. Otolaryngol Head Neck Surg 106:181-188

Meunier N, Raynaud A, Le Bourhis M et al (2020) The olfactory mucosa, first actor of olfactory detection, is sensitive to glucocorticoid hormone. Eur J Neurosci 51:1403-1418. https://doi. org/10.1111/ejn.14564

Miller ML, Andringa A, Evans JE, Hastings L (1995) Microvillar cells of the olfactory epithelium: morphology and regeneration following exposure to toxic compounds. Brain Res 669:1-9. https://doi. org/10.1016/0006-8993(94)01144-7

Mitchell GB, Clark ME, Lu R, Caswell JL (2011) Localization and functional characterization of pulmonary bovine odorant-binding protein. Vet Pathol 48:1054-1060. https://doi.org/10.1177/ 0300985810381907

Monjaraz-Fuentes F, Millán-Adalco D, Palomero-Rivero M et al (2017) Recovery of glomerular morphology in the olfactory bulb of young mice after disruption caused by continuous odorant exposure. Brain Res 1670:6-13. https://doi.org/10.1016/j. brainres.2017.05.030

Montalbano G, Levanti M, Abbate F et al (2020) Expression of ghrelin and leptin in the chemosensory system of adult zebrafish. Ann Anat 229:151460. https://doi.org/10.1016/j.aanat.2020.151460

Montani G, Tonelli S, Elsaesser R et al (2006) Neuropeptide Y in the olfactory microvillar cells. Eur J Neurosci 24:20-24. https://doi. org/10.1111/j.1460-9568.2006.04878.x

Morgan ET, Goralski KB, Piquette-Miller M et al (2008) Regulation of drug-metabolizing enzymes and transporters in infection, inflammation, and cancer. Drug Metab Dispos 36:205-216. https://doi. org/10.1124/dmd.107.018747

Morrison FG, Dias BG, Ressler KJ (2015) Extinction reverses olfactory fear-conditioned increases in neuron number and glomerular size. Proc Natl Acad Sci U S A 112:12846-12851. https://doi.org/10. 1073/pnas. 1505068112

Nakashima N, Nakashima K, Nakashima A, Takano M (2020) Olfactory marker protein elevates basal cAMP concentration. Biochem Biophys Res Commun 531:203-208. https://doi.org/10.1016/j. bbrc.2020.07.087

Negroni J, Meunier N, Monnerie R et al (2012) Neuropeptide Y enhances olfactory mucosa responses to odorant in hungry rats. PLoS One 7:e45266. https://doi.org/10.1371/journal.pone.0045266

Nevitt GA, Dittman AH, Quinn TP, Moody WJ (1994) Evidence for a peripheral olfactory memory in imprinted salmon. Proc Natl
Acad Sci U S A 91:4288-4292. https://doi.org/10.1073/pnas.91. 10.4288

Ogura T, Szebenyi SA, Krosnowski K et al (2011) Cholinergic microvillous cells in the mouse main olfactory epithelium and effect of acetylcholine on olfactory sensory neurons and supporting cells. J Neurophysiol 106:1274-1287. https://doi.org/10.1152/ jn.00186.2011

Ohkuma M, Kawai F, Miyachi E (2013) Acetylcholine enhances excitability by lowering the threshold of spike generation in olfactory receptor cells. J Neurophysiol 110:2082-2089. https://doi.org/10. 1152/jn.01077.2012

Ohshima K, Hiramatsu K (2000) Distribution of T-cell subsets and immunoglobulin-containing cells in nasal-associated lymphoid tissue (NALT) of chickens. Histol Histopathol 15:713-720. https://doi.org/10.14670/HH-15.713

Palouzier-Paulignan B, Lacroix MC, Aimé P et al (2012) Olfaction under metabolic influences. Chem Senses 37:769-797. https:// doi.org/10.1093/chemse/bjs059

Peng T, Chanthaphavong RS, Sun S et al (2017) Keratinocytes produce IL-17c to protect peripheral nervous systems during human HSV-2 reactivation. J Exp Med 214:2315-2329. https://doi.org/ 10.1084/jem.20160581

Pfister S, Weber T, Härtig W et al (2015) Novel role of cystic fibrosis transmembrane conductance regulator in maintaining adult mouse olfactory neuronal homeostasis. J Comp Neurol 523:406-430. https://doi.org/10.1002/cne.23686

Pifferi S, Boccaccio A, Menini A (2006) Cyclic nucleotide-gated ion channels in sensory transduction. FEBS Lett 580:2853-2859. https://doi.org/10.1016/j.febslet.2006.03.086

Pozharskaya T, Liang J, Lane AP (2013) Regulation of inflammationassociated olfactory neuronal death and regeneration by the type II TNF receptor. Int Forum Allergy Rhinol 3:740-747. https://doi.org/10.1002/alr.21187

Rattazzi L, Cariboni A, Poojara R et al (2015) Impaired sense of smell and altered olfactory system in RAG-1(-/-) immunodeficient mice. Front Neurosci 9:318. https://doi.org/10.3389/ fnins.2015.00318

Raynaud A, Meunier N, Acquistapace A, Bombail V (2015) Chronic variable stress exposure in male Wistar rats affects the first step of olfactory detection. Behav Brain Res 291:36-45. https://doi. org/10.1016/j.bbr.2015.05.013

Reisert J, Reingruber J (2019) Ca2+-activated Cl- current ensures robust and reliable signal amplification in vertebrate olfactory receptor neurons. Proc Natl Acad Sci USA 116:1053-1058. https://doi.org/10.1073/pnas.1816371116

Robert-Hazotte A, Faure P, Neiers F et al (2019) Nasal mucus glutathione transferase activity and impact on olfactory perception and neonatal behavior. Sci Rep 9:3104. https://doi.org/10.1038/ s41598-019-39495-6

Rodriguez S, Cao L, Rickenbacher GT, et al (2020) Innate immune signaling in the olfactory epithelium reduces odorant receptor levels: modeling transient smell loss in COVID-19 patients. medRxiv. https://doi.org/10.1101/2020.06.14.20131128

Rotermund N, Schulz K, Hirnet D, Lohr C (2019) Purinergic signaling in the vertebrate olfactory system. Front Cell Neurosci 13:112. https://doi.org/10.3389/fncel.2019.00112

Ruitenberg MJ, Vukovic J, Blomster L et al (2008) CX3CL1/fractalkine regulates branching and migration of monocyte-derived cells in the mouse olfactory epithelium. J Neuroimmunol 205:80-85. https://doi.org/10.1016/j.jneuroim.2008.09.010

Rumeau C, Nguyen DT, Jankowski R (2016) How to assess olfactory performance with the Sniffin' Sticks test $\left({ }^{\circledR}\right)$. Eur Ann Otorhinolaryngol Head Neck Dis 133:203-206. https://doi.org/10. 1016/j.anorl.2015.08.004

Rustenhoven J, Kipnis J (2019) Smelling danger: olfactory stem cells control immune defense during chronic inflammation. 
Cell Stem Cell 25:449-451. https://doi.org/10.1016/j.stem. 2019.09.006

Saunders CJ, Christensen M, Finger TE, Tizzano M (2014) Cholinergic neurotransmission links solitary chemosensory cells to nasal inflammation. Proc Natl Acad Sci U S A 111:6075-6080. https:// doi.org/10.1073/pnas.1402251111

Schöpf V, Kollndorfer K, Pollak M et al (2015) Intranasal insulin influences the olfactory performance of patients with smell loss, dependent on the body mass index: a pilot study. Rhinology 53:371-378. https://doi.org/10.4193/Rhin15.065

Schwartz M, Menetrier F, Heydel JM et al (2020) Interactions between odorants and glutathione transferases in the human olfactory cleft. Chem Senses 45:645-654. https://doi.org/10.1093/chemse/ bjaa055

Selvaraj S, Liu K, Robinson AM, et al (2012) In vivo determination of mouse olfactory mucus cation concentrations in normal and inflammatory states. PLoS One 7. https://doi.org/10.1371/journal.pone. 0039600

Semke E, Distel H, Hudson R (1995) Specific enhancement of olfactory receptor sensitivity associated with foetal learning of food odors in the rabbit. Naturwissenschaften 82:148-149. https://doi. org/10.1007/BF01177279

Sepahi A, Salinas I (2016) The evolution of nasal immune systems in vertebrates. Mol Immunol 69:131-138. https://doi.org/10.1016/j. molimm.2015.09.008

Shin T, Kim J, Ahn M, Moon C (2019) Olfactory dysfunction in CNS neuroimmunological disorders: a review. Mol Neurobiol 56:3714-3721. https://doi.org/10.1007/s12035-018-1341-0

Sollai G, Melis M, Magri S et al (2019) Association between the rs2590498 polymorphism of odorant binding protein (OBPIIa) gene and olfactory performance in healthy subjects. Behav Brain Res 372:112030. https://doi.org/10.1016/j.bbr.2019.112030

Stanke-Labesque F, Gautier-Veyret E, Chhun S et al (2020) Inflammation is a major regulator of drug metabolizing enzymes and transporters: consequences for the personalization of drug treatment. Pharmacol Ther 215:107627. https://doi.org/10.1016/j. pharmthera.2020.107627

Tacchi L, Musharrafieh R, Larragoite ET et al (2014) Nasal immunity is an ancient arm of the mucosal immune system of vertebrates. Nat Commun 5:5205. https://doi.org/10.1038/ncomms6205

Terral G, Marsicano G, Grandes P, Soria-Gómez E (2020) Cannabinoid control of olfactory processes: the where matters genes (Basel) 11. https://doi.org/10.3390/genes 11040431

Torabi A, Mohammadbagheri E, Akbari Dilmaghani N et al (2020) Proinflammatory cytokines in the olfactory mucosa result in COVID-19 induced anosmia. ACS Chem Neurosci. https://doi. org/10.1021/acschemneuro.0c00249

Turner JH, May L, Reed RR, Lane AP (2010) Reversible loss of neuronal marker protein expression in a transgenic mouse model for sinusitis-associated olfactory dysfunction. Am J Rhinol Allergy 24:192-196. https://doi.org/10.2500/ajra.2010.24.3460

Ualiyeva S, Hallen N, Kanaoka Y, et al (2020) Airway brush cells generate cysteinyl leukotrienes through the ATP sensor P2Y2 Sci Immunol 5. https://doi.org/10.1126/sciimmunol.aax7224

van der Linden C, Jakob S, Gupta P et al (2018) Sex separation induces differences in the olfactory sensory receptor repertoires of male and female mice. Nat Commun 9:5081. https://doi.org/10.1038/ s41467-018-07120-1

van der Linden CJ, Gupta P, Bhuiya AI et al (2020) Olfactory stimulation regulates the birth of neurons that express specific odorant receptors. Cell Rep 33:108210. https://doi.org/10.1016/j.celrep. 2020.108210

Villar PS, Delgado R, Vergara C et al (2017) Energy Requirements of odor transduction in the chemosensory cilia of olfactory sensory neurons rely on oxidative phosphorylation and glycolytic processing of extracellular glucose. J Neurosci 37:5736-5743. https://doi.org/10.1523/JNEUROSCI.2640-16.2017

Vogalis F, Hegg CC, Lucero MT (2005) Ionic conductances in sustentacular cells of the mouse olfactory epithelium. J Physiol (Lond) 562:785-799. https://doi.org/10.1113/jphysiol.2004.079228

Wakisaka N, Miyasaka N, Koide T et al (2017) An adenosine receptor for olfaction in fish. Curr Biol 27:1437-1447.e4. https://doi.org/ 10.1016/j.cub.2017.04.014

Wang HW, Wysocki CJ, Gold GH (1993) Induction of olfactory receptor sensitivity in mice. Science 260:998-1000. https://doi.org/10. 1126/science.8493539

Wang Q, Titlow WB, McClintock DA et al (2017) Activity-dependent gene expression in the mammalian olfactory epithelium. Chem Senses 42:611-624. https://doi.org/10.1093/chemse/bjx028

Watt WC, Sakano H, Lee ZY et al (2004) Odorant stimulation enhances survival of olfactory sensory neurons via MAPK and CREB. Neuron 41:955-967

Wu D, Bleier BS, Wei Y (2018) Temporary olfactory improvement in chronic rhinosinusitis with nasal polyps after treatment. Eur Arch Otorhinolaryngol 275:2193-2202. https://doi.org/10.1007/ s00405-018-5066-5

Xu PS, Lee D, Holy TE (2016) Experience-dependent plasticity drives individual differences in pheromone-sensing neurons. Neuron 91:878-892. https://doi.org/10.1016/j.neuron.2016.07.034

Yoo F, Soler ZM, Mulligan JK et al (2019) Olfactory cleft mucus proteins associated with olfactory dysfunction in a cohort without chronic rhinosinusitis. Int Forum Allergy Rhinol 9:1151-1158. https://doi.org/10.1002/alr.22391

Yoshikawa K, Wang H, Jaen C et al (2018) The human olfactory cleft mucus proteome and its age-related changes. Sci Rep 8:17170. https://doi.org/10.1038/s41598-018-35102-2

Yu Y, Zhang C (2014) Purinergic signaling negatively regulates activity of an olfactory receptor in an odorant-dependent manner. Neuroscience 275:89-101. https://doi.org/10.1016/j.neuroscience. 2014.05.055

Yu Y, Zhang C (2015) The role of connexin 43 in mediating odor response. Eur J Cell Biol 94:267-275. https://doi.org/10.1016/j. ejcb.2015.04.001

Yu YY, Kong W, Yin YX et al (2018) Mucosal immunoglobulins protect the olfactory organ of teleost fish against parasitic infection. PLoS Pathog 14:e1007251. https://doi.org/10.1371/journal.ppat. 1007251

Zhang C (2010) Gap junctions in olfactory neurons modulate olfactory sensitivity. BMC Neurosci 11:108. https://doi.org/10.1186/ 1471-2202-11-108

Zhao H, Reed RR (2001) X inactivation of the OCNC1 channel gene reveals a role for activity-dependent competition in the olfactory system. Cell 104:651-660. https://doi.org/10.1016/s00928674(01)00262-8

Zhao S, Tian H, Ma L et al (2013) Activity-dependent modulation of odorant receptor gene expression in the mouse olfactory epithelium. PLoS ONE 8:e69862. https://doi.org/10.1371/journal. pone.0069862

Zou J, Wang W, Pan Y-W, et al (2015) Methods to measure olfactory behavior in mice. Curr Protoc Toxicol 63:11.18.1-11.18.21. https://doi.org/10.1002/0471140856.tx1118s63

Publisher's Note Springer Nature remains neutral with regard to jurisdictional claims in published maps and institutional affiliations. 